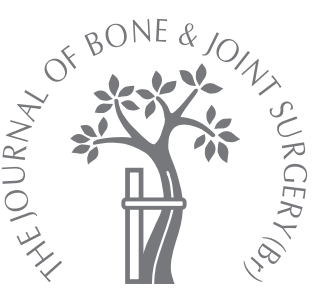

M. Clauss,

T. Ilchmann,

P. Zimmermann,

P. E. Ochsner

From Department for Orthopaedic Surgery, Kantonsspital Liestal, Liestal, Switzerland

M. Clauss, MD, Orthopaedic Surgeon

T. Ilchmann, MD, PhD Orthopaedic Surgeon, Co-Head of Department

P. E. Ochsner, MD,

Orthopaedic Surgeon

Professor, Former Head of

Department

Kantonsspital Liestal,

Rheinstrasse 26, $\mathrm{CH}-4410$

Liestal, Switzerland.

- P. Zimmermann, Technician Anatomic Institute

University of Basel, Pestalozzi

Street 20, CH-4051 Basel,

Switzerland.

Correspondence should be sent to Dr M. Clauss; e-mail: martin.clauss@ksli.ch

(C)2010 British Editorial Society of Bone and Joint Surgery doi:10.1302/0301-620X.92B11. $25342 \$ 2.00$

$J$ Bone Joint Surg $[\mathrm{Br}]$ 2010;92-B:1515-21.

Received 16 October 2009,

Accepted 15 June 2010

\title{
The histology around the cemented Müller straight stem
}

\author{
A POST-MORTEM ANALYSIS OF EIGHT WELL-FIXED STEMS WITH \\ A MEAN FOLLOW-UP OF 12.1 YEARS
}

The aim of this study was to obtain detailed long-term data on the cement-bone interface in patients with cemented stems, implanted using the constrained fixation technique. A total of eight stems were removed together with adjacent bone during post-mortem examinations of patients with well-functioning prostheses. Specimens were cut at four defined levels, contact radiographs were obtained for each level, and slices were prepared for histological analysis. Clinical data, clinical radiographs, contact radiographs and histological samples were examined for signs of loosening and remodelling. The mean radiological follow-up was 9.6 years and all stems were well-fixed, based on clinical and radiological criteria. Contact radiographs revealed an incomplete cement mantle but a complete filling of the medullary canal for all implants. Various amounts of polyethylene particles were evident at the cement-bone interface of seven stems, with no accompanying inflammatory reaction. Cortical atrophy and the formation of an 'inner cortex' were confirmed in six of eight stems by contact radiographs and histology, but were only visible on two clinical radiographs.

Our results confirm that a complete cement mantle is not essential for the survival of Müller straight stems into the mid term, and support our hypothesis that no benefit to longterm survival can be expected from modern cementing techniques.

The long-term success of a cemented hip stem depends on the survival of the cement-bone and the cement-prosthesis interfaces. ${ }^{1,2}$ The various anchoring concepts for cemented stems can be categorised as 'contained' or 'constrained', ${ }^{3,4}$ depending on the shape, thickness and completeness of the cement mantle. ${ }^{1,5}$

The Müller straight stem (Zimmer, Winterthur, Switzerland) was designed to achieve a press-fit fixation with a self-centring effect in the anteroposterior (AP) view and close stembone contact in the coronal plane. This results in a thin, often incomplete cement mantle. ${ }^{6,7} \mathrm{It}$ is known that incomplete cement mantles are associated with an increased risk of loosening in patients with contained stems. ${ }^{5}$ Conversely, constrained systems with an incomplete cement mantle, such as the Müller straight stem $(\mathrm{CoNiCr})$, have been associated with excellent long-term clinical and radiological results. ${ }^{6,8,9}$ This inconsistency in the relationship between the completeness of the cement mantle and long-term success for the two types of implants is known as the 'French paradox'.

Radiological changes around total hip replacements (THRs) are frequently observed. The amount and the extent of changes correlate with the duration of follow-up. Some changes, such as osteolysis and debonding, are established risk factors for aseptic loosening of cemented stems. ${ }^{6,10,11}$ Others, such as stress shielding, are related to spatial differences in strain patterns in the proximal femur, determined by the shape of the stem. Furthermore, age-related radiological changes commonly occur at the proximal femur with and without the presence of any kind of THR. ${ }^{12}$ Post mortem retrieval studies of well-functioning THRs are essential to achieve a better understanding of the radiological changes that occur over the long term, as well as the relationship between methods of fixation and long-term outcome. ${ }^{7,13-18}$

We investigated the histological appearance around eight cemented Müller straight stems (CoNiCr) removed from deceased patients. No signs of clinical or radiological failure had been observed for any of the implants. Our aim of this was to obtain detailed long-term data on the cement-bone interface in patients with canal-filling cemented stems, implanted in a constrained fashion. ${ }^{7}$ We were particularly interested in assessing the frequency and distribution of osteolysis, debonding and cortical 


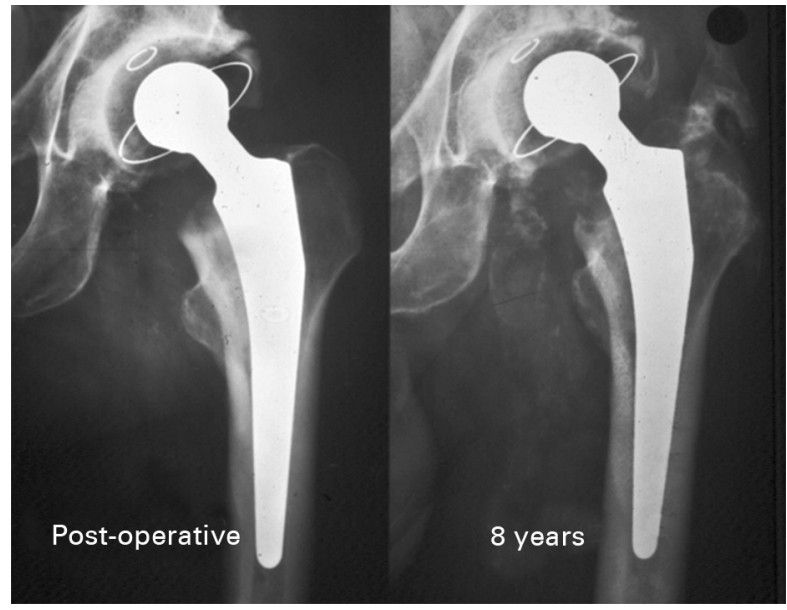

Fig. 1a

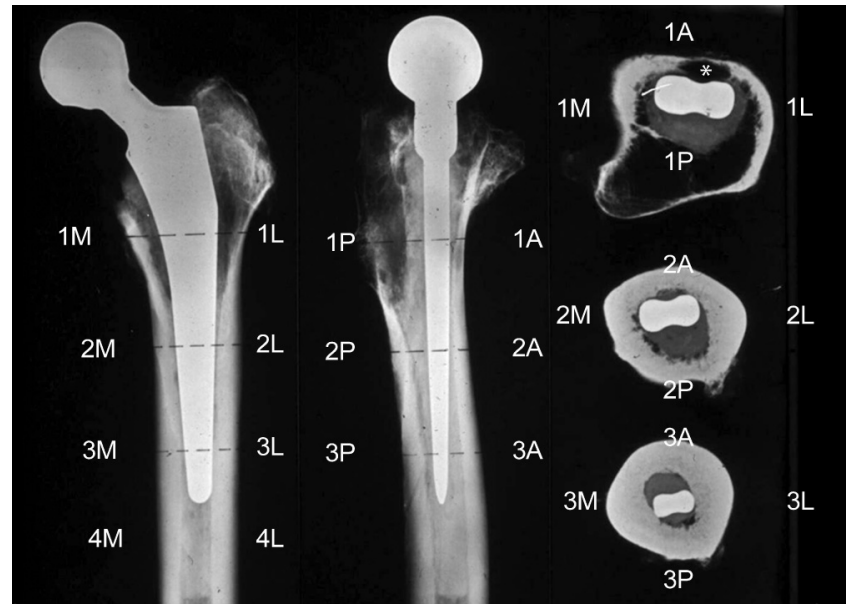

Fig. 1b

Figuere 1a - clinical radiographs (post-operative and eight-year follow-up) of an 85-year-old man who died 12.6 years after implantation. Showing no radiological changes (debonding, osteolysis or cortical atrophy), polyethylene wear $0.13 \mathrm{~mm} /$ year. Figure $1 \mathrm{~b}-\mathrm{specimen}$ radiographs indicating cutting heights (levels 1, 2 and 3 ) and allocation of areas (lateral (L), medial (M), anterior (A), and posterior (P)). Contact radiographs show a gap in the cement mantle in areas $2 \mathrm{~L}, 2 \mathrm{~A}, 2 \mathrm{M}, 3 \mathrm{~L}$ and $3 \mathrm{M}$, with no signs of cortical atrophy. A gap is evident between the cement and the cortex in areas $1 \mathrm{P}, 2 \mathrm{P}$ and $3 \mathrm{P}$, with massive polyethylene particles in areas $1 \mathrm{P}$ and $1 \mathrm{~L}$. A bead-shaped cortical defect is evident in area $1 \mathrm{~A}$ (asterisk), confirmed to be osteolysis on histological samples.

atrophy, and establishing whether these processes correlate with radiological changes.

\section{Patients and Methods}

Between July 1984 and June 1987, 165 primary THRs were performed in 161 patients using the Müller straight stem (CoNiCr) and their progress was followed prospectively. A standard transgluteal approach ${ }^{6}$ was used in all cases and the implants were placed using a distal cement plug, retrograde introduction of cement with a syringe, and hand-mixed lowviscosity cement (Sulfix 6, Zimmer). The implants were cemented in line with the final broach, ${ }^{9}$ but in contrast to other canal-filling implants, no cancellous bone was removed in the sagittal plane. ${ }^{9,19}$ Clinical and radiological follow-up was undertaken in a standardised manner, the long-term results of which were recently published. ${ }^{6,20}$

The seven patients whose implants (eight stems) provided the basis for this study died for reasons unrelated to the THR. All post-mortem examinations were performed at our hospital, during which the stems and surrounding bone tissue were retrieved. The collection of human anatomical material was performed in accordance with national and institutional regulations.

The soft tissue was mechanically removed from the bone and radiographs were taken to determine the location of the Gruen zones. ${ }^{21}$ The cutting height was calculated from the radiographs and located precisely in the middle of the Gruen zones (Fig. 1). Slices $8 \mathrm{~mm}$ thick were obtained from horizontal cuts using an Exakt 310 diamond bandsaw (Exakt, Norderstedt, Germany). The proximal slice (level 1), located in the middle of the proximal Gruen zones and bisecting the lesser trochanter, represents an area of cortical and cancellous bone. The middle (level 2) and distal (level 3) slices represent areas where direct stem-bone contact is expected to be frequent, both medially and laterally. An additional slice (level 4) was taken in the frontal plane from the tip of the stem to the cement plug.

Contact radiographs were taken of each of the four $8 \mathrm{~mm}$ slices. The three horizontal cuts were analysed, describing lateral (L), medial (M), anterior (A), and posterior $(\mathrm{P})$ areas (Fig. 1b). The frontal cut was divided into a medial (M) and a lateral (L) area. All cuts were assessed for completeness of the cement mantle, direct stem-cortex contact, and the presence of bead-shaped bony defects, defined as osteolysis. The thickness of the cement mantle and the distance between the outer border of the cement and the inner border of the cortex were measured perpendicular to the surface of the implant in all four areas of the proximal three levels (Fig. 1b). Extension of cancellous areas relative to the cortex was measured and rated as follows: samples exhibiting no extension of the cancellous area (grade 0), samples showing an extension of the cancellous area corresponding to less than one-third of the thickness of the cortex (grade I), samples showing extension corresponding to between one-third and two-thirds of cortex thickness (grade II), and samples with extension of more than twothirds of cortex thickness (grade III). All contact radiographs were compared with the clinical radiographs.

The $8 \mathrm{~mm}$ thick slices were embedded in Araldite K83 (Vantico AG, Basel, Switzerland) under vacuum conditions. The slices were then fixed and cut to a thickness of $1 \mathrm{~mm}$ before grinding and polishing to a final thickness of about $200 \mu \mathrm{m}$ (Exakt R grinding system, Exakt).

Additional $5 \mathrm{~mm}$ thick slices were cut distally adjacent to the $8 \mathrm{~mm}$ slices of levels 1, 2 and 3, and embedded in polymethylmethacrylate (PMMA) for histological 
preparation. Following removal of the implant, they were further cut with a K-microtome (Leica AG, Heerbrugg, Switzerland) to a thickness of about $5 \mu \mathrm{m} .^{22}$

All samples were stained using the method of Romanovski. ${ }^{23}$ The Araldite specimens were additionally stained with Goldner's trichrome. ${ }^{23}$

Samples were analysed as whole-mount sections using an Olympus SZH-ILLH, and in details using an Olympus VanoxS microscope (Olympus AG, Volketswil, Switzerland) combined with a digital camera (Leica DFC 420, Leica $A G$ ). Images were stored in Image access 2.0 (Imagic AG, Opfikon, Switzerland).

Histological samples were taken from each area of each level of the stems, namely the medial, lateral, anterior and posterior areas of levels 1 to 3 and medial and lateral of level 4. The Araldite samples were analysed for osteolysis, defined as a cystic lesion without trabeculae, expanding $3 \mathrm{~mm}$ and with a fibrous tissue coating. The cement-bone interface was further assessed for the presence of layers of fibrous tissue. These were described as none, thin or thick, according to the definitions of Charnley. ${ }^{17}$ The thickness of the cement mantle was measured perpendicular to the surface of the implant at all four areas in the proximal three levels, as described for the contact radiographs. The cortex was assessed for atrophy ${ }^{15}$ and graded in a corresponding way to the contact radiographs. Samples showing no atrophy were graded as zero, samples showing atrophy corresponding to less than one-third of cortex thickness were graded I, samples showing atrophy corresponding to between one-third and two-thirds of cortex thickness were graded II, and samples with atrophy of more than two thirds of cortex thickness were graded III. The histological samples were also analysed for the presence of an 'inner' cortex. $^{24}$

The $5 \mu \mathrm{m}$ slices were assessed using polarised light for the presence of both polyethylene and metal wear particles. The quantities of polyethylene and metal wear particles found were described as none, mild or massive.

All histological findings were compared with the findings on the contact and clinical radiographs.

All measurements were undertaken with a calliper. Values are presented as means (SD) or median and range.

\section{Results}

All seven patients (five men and two women) had a complete clinical and radiological follow-up until the time of death. The mean duration of clinical follow-up was 12.1 years (8.7 to 13.6 ) and of radiological follow-up was 9.6 years $(6.2$ to 10.2$)$. The mean time between the last follow-up and death was 2.5 years (1.8 to 3.5$)$.

The indications for THR included osteoarthritis (six cases), slipped femoral epiphysis (one) and femoral head necrosis (one). The mean age at operation was 69.6 years (59.8 to 77.8$)$ and the mean age at death was 81.8 years (68.5 to 90.2). Six stems were implanted in men, four were placed on the right side and one man had bilateral
THR. A standard offset was used in five cases and a lateralised version in three, all in combination with a $32 \mathrm{~mm}$ head made of CoNiCr $(n=5)$ or ceramic $(n=3)$. The eight stems were implanted together with cemented polyethylene cups.

Causes of death included cerebrovascular insult (two patients), heart attack (two), a malignancy (two) and pneumonia. The patient with femoral head necrosis had undergone acetabular revision due to aseptic loosening at 3.5 years and had no further problems until death 13 years after the index operation. An 88-year-old man was also determined to have a loose cup at 10.2 years. However, as he was pain free, he was not scheduled for revision and died without further complaints relevant to the implant, 12.4 years after THR. The loose cup was confirmed at the postmortem examination.

Clinical. The median Harris hip score (HHS $)^{25}$ was 83 points (97 to 73 ). Two patients complained of slight pain in the operated hip at the last follow-up.

Radiological. Clinical radiographs. The axis was determined to be neutral in all stems and none showed debonding or subsidence. Osteolysis was evident in two stems. Radiographs of one from a male patient showed osteolysis in Gruen zones 6 and 7. Radiographs of the other, from a female patient, showed osteolysis in Gruen zones 7 and 1 (Fig. 2). In both cases radiographic evidence of osteolysis was first observed at the ten-year follow-up. The mean polyethylene wear among the eight hips was $1.0 \mathrm{~mm}$ (SD $0.7)$. The mean annual polyethylene wear was $0.1 \mathrm{~mm} /$ year (SD 0.07). The highest rate of wear was $0.26 \mathrm{~mm} /$ year (total wear $2.57 \mathrm{~mm}$ ), detected in a male patient who had osteolysis and a loose cup at final follow-up. Cortical atrophy was detectable on the clinical radiographs of both female patients, but on none of the radiographs of the male patients. For one stem, cortical atrophy was found in Gruen zones 1, 2, 6 and 7 (Fig. 2) and for the other in Gruen zones 2, 3, 5 and 6 (Fig. 3).

Contact radiographs. Direct stem-bone contact was found in all eight stems, mainly in the areas $2 \mathrm{M}, 3 \mathrm{M}$ and $3 \mathrm{P}$. In the sagittal plane thickness of the cement mantle was heterogeneous, with the thinnest mantles in zones $1 \mathrm{~A}, 2 \mathrm{~A}$ and 3P, without visible cracks. We found almost no gap between the cement mantle and the inner cortex at levels 2, 3 and 4, except in one man (Fig. 1) who showed a groove in the dorsal area of all three levels (1P, 2P, 3P). One man showed osteolysis in areas $1 \mathrm{M}$ and $2 \mathrm{M}$, and one woman in areas $1 \mathrm{P} / \mathrm{M}$ and $1 \mathrm{~A} / \mathrm{L}$ (Fig. 2). Debonding was evident in one female patient at locations $1 \mathrm{~A}, 1 \mathrm{P}$ and $2 \mathrm{P}$ (Fig. 2), and in one male patient at location 1P. Cortical atrophy was detectable in all but two male patients. The extent of atrophy varied considerably. The two women with cortical atrophy on the clinical radiographs had grade III cortical atrophy on the contact radiographs. Initiation of cortical atrophy (grade I) was always located in the inner third of the cortex, expanding radially to the inner two-thirds in grade II. 


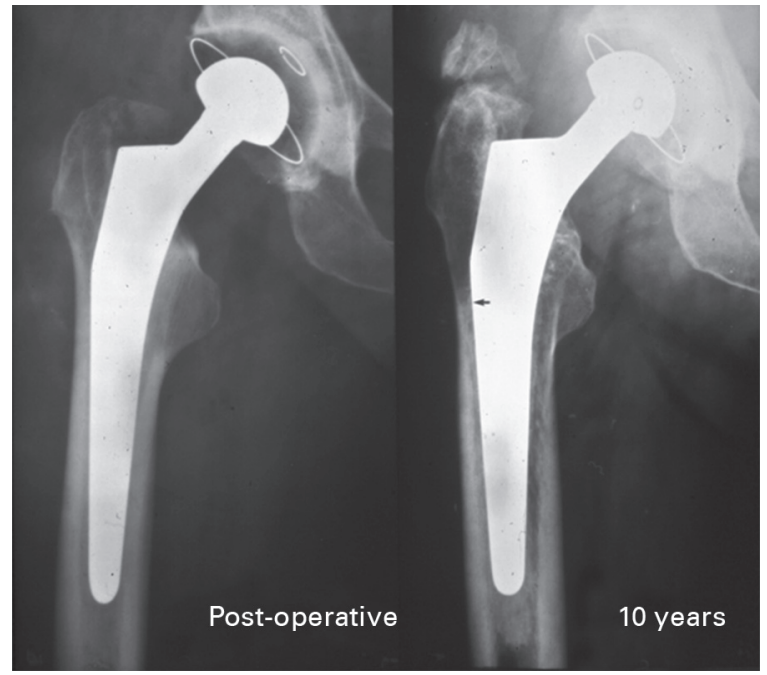

Fig. 2a

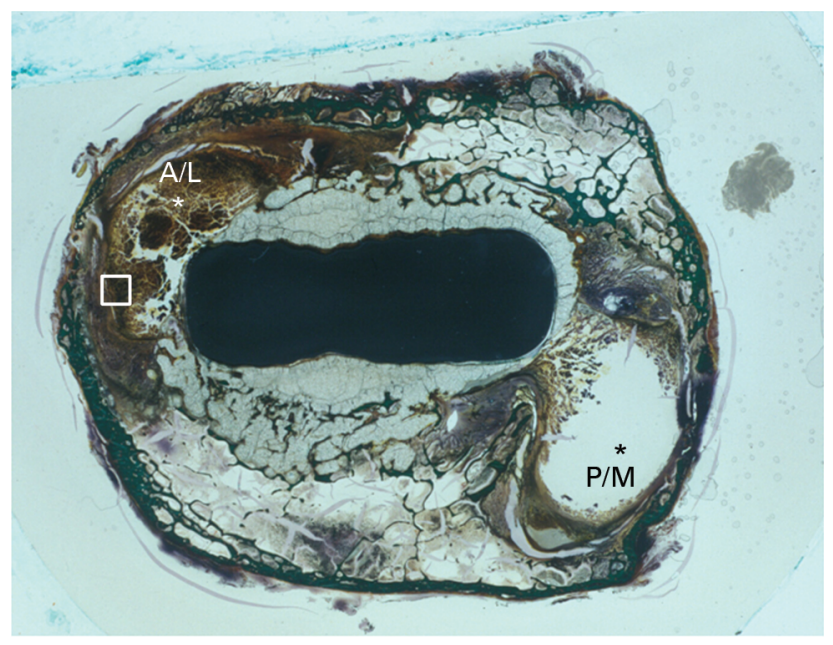

Fig. 2c

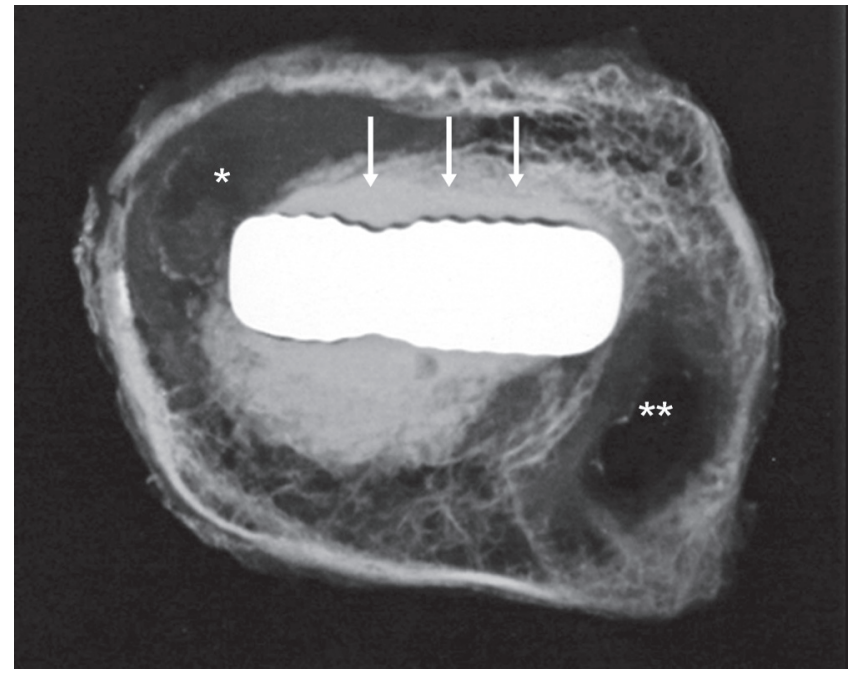

Fig. 2b

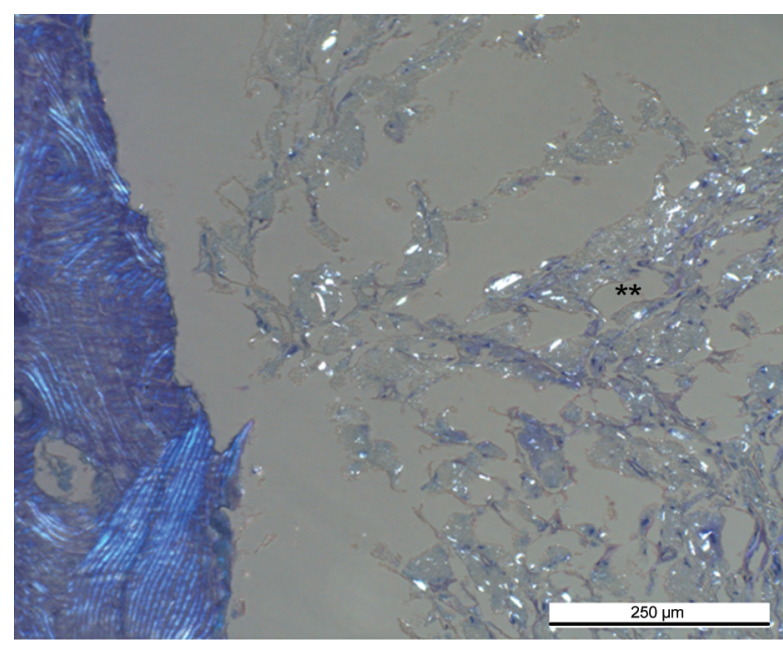

Fig. 2d

Figure 2a - clinical radiographs (post-operative and ten-year follow-up) of an 85-year-old woman, who died 13.2 years after operation. Osteolysis without debonding is evident in Gruen zones 1 and 7. Cortical atrophy is seen in Gruen zones 1, 2, 6 and 7. Figure 2b-contact radiograph (level 1) indicating osteolysis in areas $1 \mathrm{~A} / 1 \mathrm{~L}\left({ }^{*}\right)$ and $1 \mathrm{P} / 1 \mathrm{M}\left({ }^{*}\right)$ and an incomplete cement mantle with slight debonding in areas $1 \mathrm{P} / 1 \mathrm{M}$ and $1 \mathrm{~A} / 1 \mathrm{~L}($ arrows point to area 1A). Figure $2 \mathrm{c}$ - image of a sample used for histological assessment (level 1, $200 \mu \mathrm{m}$, Goldner's staining) indicating the location of osteolysis (*) in areas $1 \mathrm{P} / 1 \mathrm{M}$ and $1 \mathrm{~A} / 1 \mathrm{~L}$. Figure $2 \mathrm{~d}-$ image of a sample used for detailed histological assessment (level 1, $5 \mu \mathrm{m}$, Romanovski staining, polarised light) indicating the location of a massive amount of polyethylene wear particles (**, area $1 \mathrm{~A} / 1 \mathrm{~L}$, box Fig. $2 \mathrm{c})$.

Histological findings. Histological analysis confirmed osteolysis in both patients whose clinical and contact radiographs showed evidence of osteolysis. All eight stems had an incomplete cement mantle and direct stem-bone contact (Figs 2 and 3). Cement mantle thickness, gaps between cement mantle and cortex, and gaps in the cement mantle corresponded to the contact radiographs.

Cortical atrophy was evident in six stems (Figs 2 and 3). Grade I atrophy was present in the inner third of the cortex and grade II atrophy was evident in the inner two-thirds of the cortex of all affected stems, corresponding to the findings on the contact radiographs. The formation of an 'inner-cortex ${ }^{24}$ was rare, even in cases of severe cortical atrophy (Fig. 3). A large amount of blood-forming bone marrow was found in one woman, associated with the cortical atrophy surrounding the proximal and middle areas of the stem (Fig. 3).

Mild amounts of polyethylene particles were found at the cement-bone interface in seven stems (Fig. 2). Huge amounts of these particles were found only at level one of the two patients with osteolysis, and in the patient with the loose cup at final follow-up. The mean rate of polyethylene wear in these three patients increased about threefold $(0.18 \mathrm{~mm} /$ year (SD 0.08)) compared to the other five patients $(0.06 \mathrm{~mm} /$ year (SD 0.02))

Zirconium particles derived from the cement (Fig. 3) and CoNiCr particles from the stem were found in all specimens 


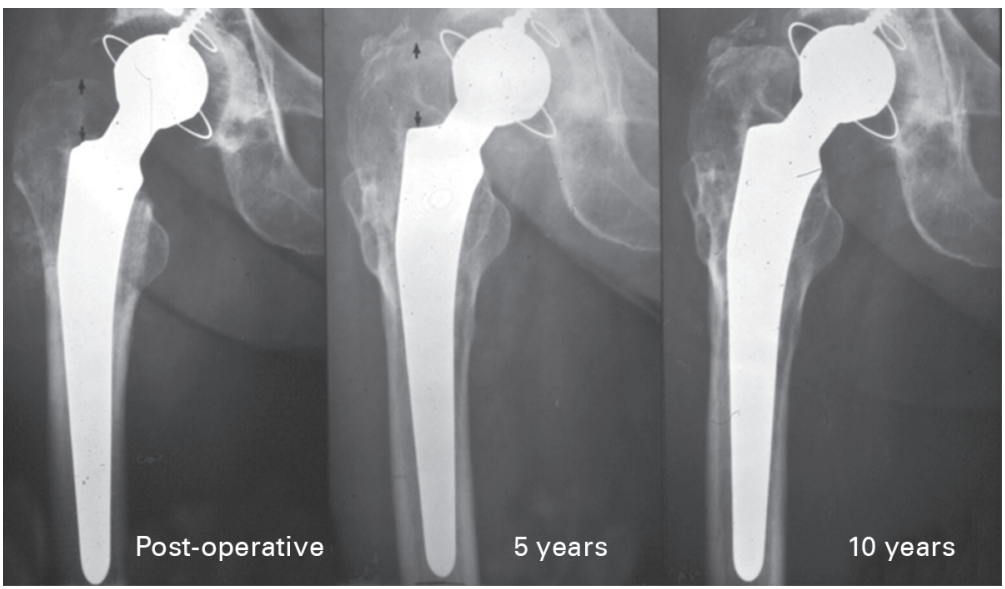

Fig. 3a

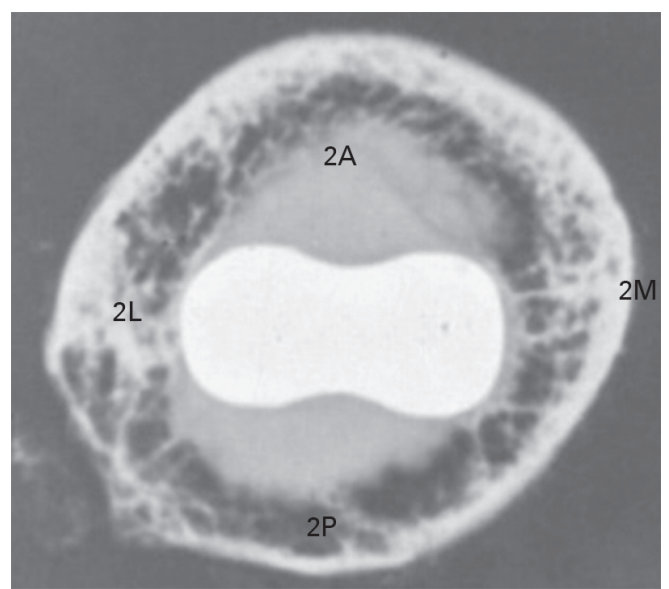

Fig. 3b

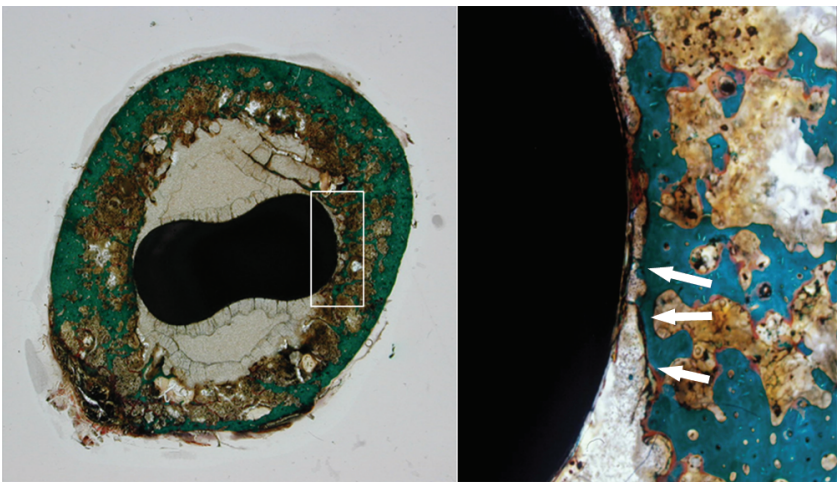

Fig. 3c

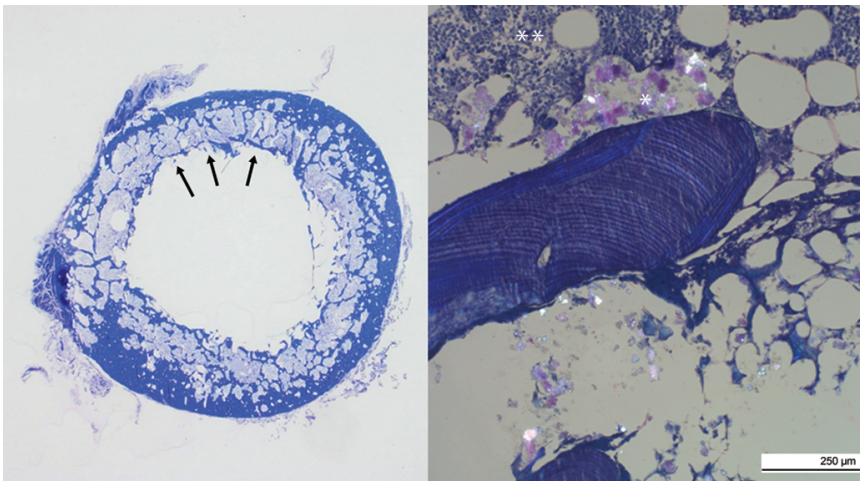

Fig. 3d

Figure $3 a$ - clinical radiographs (post-operative, five- and ten-year follow-up) of an 80-year-old woman, who died 13.6 years after operation. No signs of loosening were observed during follow-up. Cortical atrophy was evident in Gruen zones 2, 3, 5 and 6 . Figure $3 \mathrm{~b}-\mathrm{contact}$ radiograph (level 2) showing contact at the cement-implant interface without debonding. Cortical atrophy (grade III) is evident in areas $2 \mathrm{~A}, 2 \mathrm{P}, 2 \mathrm{M}$ and $2 \mathrm{~L}$. Figure $3 \mathrm{c}-$ images of a sample used for histological assessment (level 2, $200 \mu \mathrm{m}$, Goldner's staining); detailed image shows an area with an incomplete cement mantle (area $2 \mathrm{M}$ ) and a thin layer of fibrous tissue at the cement-bone interface. Figure $3 \mathrm{~d}$ - image of a sample used for detailed histological assessment (level 2, $5 \mu \mathrm{m}$, Romanovski staining) indicating slight formation of an 'inner cortex' (arrows); detailed image (polarised light) shows bone trabeculae with zirconium particles $(*)$ and regular blood-forming bone marrow $\left({ }^{*}\right)$.

with a heterogeneous, non-specific distribution. There was no evidence of an inflammatory reaction around these metal particles for any of the stems.

\section{Discussion}

The seven patients in this series are representative of the entire series ${ }^{6}$ with respect to the clinical and radiological outcome, and none received, or was scheduled for, any procedure due to problems from the stem. This series therefore represents well-functioning Müller straight stems at the mid term. Histological examinations of tissues surrounding hip implants are rare. To our knowledge, our series and the analysis published by Charnley ${ }^{17}$ comprise the only histological studies providing prospective clinical and radiological data on tissues surrounding well-functioning stems. In contrast to other histological studies ${ }^{15,16,26,27}$ this series involves patients treated with a single implant and cementing concept. ${ }^{7}$
The limitations of this study include the small number of patients and the time between the latest clinical and radiological follow-up and the histological examination after death. Although such a period cannot be avoided, it is possible that changes around the stem might have occurred during this time. However, it can be speculated that most changes occur during the more active period of life, rather than during the last year.

The implantation method in this study used the largest possible stem that would fit the femoral canal. This technique, along with the stem design, makes gross errors in varus-valgus orientation almost impossible, and results in a situation where the implant itself almost fills the canal in the coronal plane, resulting in a very thin and incomplete cement mantle. ${ }^{6}$ As expected, the cement mantle was thinnest in the anteroproximal (areas 1A and 2A, corresponding to Gruen zones 8 and 9) and posterodistal regions (area 3P, Gruen zone 11). This is the typical pattern seen for 
cemented straight stems, ${ }^{28,29}$ in which the stem leans from anterior to posterior in the sagittal plane. Direct stem-bone contact found medially and laterally along the length of the stem is due to the self-centring mechanism.

Several investigators have reported debonding at the cement-stem interface, fatigue fracture of the cement mantle, and aseptic loosening, mainly in areas with a thin or incomplete cement mantle, ${ }^{14,16,18}$ for stems with containedfixation. ${ }^{1,3,4}$ A complete, circumferential cement mantle is considered mandatory for the long-term survival of these stems. In contrast, the Müller straight stems that we examined are designed to achieve a constrained fixation, frequently resulting in an incomplete cement mantle.

Debonding in the coronal plane has been shown to be a risk factor for long-term aseptic loosening in the Müller straight stem, ${ }^{6}$ and is a potential first step in the cascade of aseptic loosening. No evidence of debonding was seen on the clinical AP radiographs, nor medially or laterally on the contact radiographs in this series. The only radiological evidence for debonding was found anteriorly and posteriorly on the contact radiographs, and this was only slight. Cracks in the cement mantle, signs of pending failure in the areas in question, were also not visible on the contact radiographs. ${ }^{30}$ Given that debonding is an indirect sign of micromovement at the cement-stem interface, ${ }^{31}$ the slight anterior and posterior debonding that we found may be radiological artifacts caused by preparation of the sample, as all the stems functioned well and no cracks were seen in the cement mantle in the contact radiographs.

The distribution pattern of $\mathrm{CoNiCr}$ (stem) and zirconium metal particles (bone cement) was heterogeneous and there was no apparent cellular reaction to the particles. However, metal debris is known to be associated with a severe, cellmediated inflammatory response. As there was no inflammatory reaction seen in the cells around the implant, we concluded that the metal particles were formed during the grinding step of the preparation and were not the result of micromovement. ${ }^{2}$

The "vigorous insertion of (these) canal-filling implants" is thought to result in a high intramedullary pressure, which is further increased by the use of a distal cement plug. ${ }^{19}$ Based on our analysis of the contact radiographs and histological samples, we can confirm this statement, as we found complete filling of the medullary canal and extensive cement penetration, even in the sagittal plane. The latter observation is particularly interesting, as the Müller straight stem is rather slim in the sagittal plane compared to other canal-filling implants, such as the Charnley-Kerboul prosthesis, ${ }^{19,30}$ and no further benefits can be expected from more modern cementing techniques.

However, no efforts were made to optimise the proximal cement penetration in this series. Around the proximal portion of the examined stems we found large areas with incomplete canal filling and incomplete cement penetration. Osteolysis was also found to be confined to the proximal portion of the stems. Polyethylene wear is an established risk factor for osteolysis and aseptic loosening of cemented cups, ${ }^{14}$ and to a lesser extent of stems. ${ }^{32,33}$ In the histological samples, polyethylene particles were found at the cementbone interface of all but one stem. Massive aggregates of these particles were associated with osteolysis and polyethylene wear, but small amounts showed no histological reaction. The use of a femoral seal or additional proximal fingerpacking may improve the proximal cement sealing of the medullary canal ${ }^{34}$ and reduce the amount of polyethylene particles at the interface, thereby reducing the risk of osteolysis and aseptic loosening for the Müller straight stem. ${ }^{32,33}$

Cortical atrophy, sometimes described as cortical porosis, ${ }^{5}$ is a phenomenon known to occur around cemented stems. ${ }^{6,14-16,24,27}$ Because the stems examined in this series were implanted using radio-opaque cement, mild cortical atrophy (grades 0 to II) could not be detected on clinical radiographs by the naked eye. We found complete remodelling of the cortex, including the formation of an 'inner cortex', ${ }^{24,27}$ in the two cases with severe cortical atrophy (grade III), but no effect on the integrity of the cement-bone interface ${ }^{14,16,27}$ could be discerned. Studies of other systems, ${ }^{14,15,26}$ and another study including a larger series of patients with the Müller straight stem, ${ }^{6}$ have shown that cortical atrophy is most common around the middle part of the stem (level 2). It remains unclear whether gender, ${ }^{6,35,36}$ stiffness of the implant ${ }^{26}$ or time from implantation ${ }^{15,16}$ is the most important risk factor for the development of cortical atrophy. The number of implants examined in this series is too low to provide insight into this question, but our histological findings suggest that cortical atrophy is not a risk factor for aseptic loosening of cemented stems. ${ }^{6,15,16,26,27}$ However, none of these previous studies focused on young, active patients, who may impose more stress on the interface.

\section{Supplementary material}

ё Tables showing the results of the contact radiographs and the results of histologic analysis are available with the electronic version of this article on our website at www.jbjs.org.uk

\section{Listen live \\ Listen to the abstract of this article at www.jbjs.org.uk/interactive/audio}

We wish to thank Professor Dr G. Cathomas and PD Dr S. Hailemariam, from the Institute of Pathology, Kantonsspital Liestal, for their help discussing the histological results, and Mrs S. Häfliger for her exeptional effort organising the follow-up examinations of our patients for the last 25 years.

Although none of the authors has received or will receive benefits for personal or professional use from a commercial party related directly or indirectly to the subject of this article, benefits have been or will be received but will be directed solely to a research fund, foundation, educational institution, or other non-profit organisation with which one or more of the authors are associated.

\section{References}

1. Scheerlinck T, Casteleyn PP. The design features of cemented femoral hip implants. J Bone Joint Surg [Br] 2006;88-B:1409-18.

2. Howell JR Jr, Blunt LA, Doyle C, et al. In vivo surface wear mechanisms of femoral components of cemented total hip arthroplasties: the influence of wear mechanism on clinial outcome. J Arthroplasty 2004;19:88-101.

3. Derbyshire B, Porter ML. A study of the Elite Plus femoral component using radiostereometric analysis. J Bone Joint Surg [Br] 2007;89-B:730-5. 
4. Huiskes, Verdonschot N, Nivbrant B. Migration, stem shape, and surface finish in cemented total hip arthroplasty. Clin Orthop 1998;355:730-5.

5. Breusch SJ, Aldinger PR, Thomsen M, Ewerbeck V, Lukoschek M. Anchoring principles in hip endoprostheses. I: prosthesis stem. Unfallchirurg 2000;103:918-31 (in German).

6. Clauss $\mathbf{M}$, Luem M, Ochsner PE, Ilchmann T. Fixation and loosening of the cemented Müller straight stem: a long-term clinical and radiological review. J Bone Joint Surg [Br] 2009;91-B:1158-63.

7. Langlais F, Kerboull M, Sedel L, Ling RS. The 'French paradox'. J Bone Joint Surg [Br] 2003;85-B:17-20.

8. Hamadouche M, Baqué F, Lefevre N, Kerboull M. Minimum 10-year survival of Kerboull cemented stems according to surface finish. Clin Orthop 2008;466:332-9.

9. El Masri F, Kerboull L, Kerboull M, Courpied JP, Hamadouche M. Is the socalled 'French paradox' a reality?: long-term survival and migration of the CharnleyKerboull stem cemented line-to-line. J Bone Joint Surg [Br] 2010;92-B:342-8.

10. Ebramzadeh E, Normand PL, Sangiorgio SN, et al. Long-term radiographic changes in cemented total hip arthroplasty with six designs of femoral components. Biomaterials 2003;24:3351-63.

11. Ebramzadeh E, Sarmiento A, McKellop HA, Llinas A, Gogan W. The cement mantle in total hip arthroplasty: analysis of long-term radiographic results. $J$ Bone Joint Surg [Am] 1994;76-A:77-87

12. Dorr LD, Faugere MC, Mackel AM, et al. Structural and cellular assessment of bone quality of proximal femur. Bone 1993;14:231-42.

13. Hosip-Flor S, Lester DK. Human postmortem retrieval of total hip arthroplasty. $J$ Arthroplasty 1997;12:562-7.

14. Maloney WJ, Schmalzried T, Harris WH. Analysis of long-term, cemented total hip arthroplasty retrievals. Clin Orthop 2002;405:70-8.

15. Kwong LM, Jasty M, Mulroy FRD, et al. The histology of the radiolucent line. J Bone Joint Surg [Br] 1992;74-B:67-73.

16. Schmalzried TP, Maloney WJ, Jasty M, Kwong LM, Harris WH. Autopsy stud ies of the bone-cement interface in well-fixed cemented total hip arthroplasties. Arthroplasty 1993;8:179-88.

17. Charnley J. Low friction arthroplasty of the hip: theory and practice. Berlin: SpringerVerlag, 1979:25-40

18. Kawate K, Maloney WJ, Bragdon CR, et al. Importance of a thin cement mantle: autopsy studies of eight hips. Clin Orthop 1998;355:70-6.

19. Kerboull M. The Charnley-Kerboull prosthesis. In: Postel M, Kerboull M, Evrard J, Courpied JP, eds. Total hip replacement. Berlin: Springer Verlag, 1987:13-17.

20. Riede U, Lüem M, Ilchmann T, Eucker M, Ochsner PE. The M. E. Müller straight stem prosthesis: 15 year follow-up: survivorship and clinical results. Arch Orthop Trauma Surg 2007:127:587-92.
21. Gruen TA, McNeice GM, Amstutz HC. "Modes of failure" of cemented stem-type femoral components: a radiographic analysis of loosening. Clin Orthop 1979;141:1727

22. Clauss M, Ilchmann T, Zimmermann P, et al. Classification of acetabular changes in osteoarthritis: a histological and radiological analysis of 122 consecutive drill biopsies routinely taken during THA. Surg Radiol Anat 2008;30:547-56.

23. Schenk RK, Olah AJ, Herrmann W. Preparation of calcified tissues for light microscopy. In : Dickson GR, ed. Methods of calcified tissue preparation. Amsterdam: Elsevier, 1984:1-56.

24. Charnley J. The bonding of prostheses to bone by cement. J Bone Joint Surg $[\mathrm{Br}]$ 1964;46-B:518-29

25. Harris WH. Traumatic arthritis of the hip after dislocation and acetabular fractures: treatment by mold arthroplasty: an end-result study using a new method of result evaluation. J Bone Joint Surg [Am] 1969;51-A:737-55.

26. Maloney WJ, Sychterz C, Bragdon C, et al. The Otto Aufranc: skeletal response to well fixed femoral components inserted with and without cement. Clin Orthop 1996:333:15-26.

27. Jasty M, Maloney WJ, Bragdon CR, Haire T, Harris WH. Histomorphological studies of the long-term skeletal responses to well fixed cemented femoral components. J Bone Joint Surg [Am] 1990;72-A:1220-9.

28. Clauss M, Reitzel T, Pritsch M, et al. The cemented MS-30 stem: a multi-surgeon series of 333 consecutive cases. Orthopade 2006;35:776-83 (in German).

29. Breusch SJ, Lukoschek M, Kreutzer J, Brocai D, Gruen TA. Dependency of cement mantle thickness on femoral stem designer and centralizer. J Arthroplasty 2001;16:648-57.

30. Janssen D, van Aken J, Scheerlinck T, Verdonschot N. Finite element analysis of the effect of cementing concepts on implant stability and cement fatigue failure. Acta Orthop 2009;80:319-24.

31. Verdonschot $\mathbf{N}$, Huiskes R. Surface roughness of debonded straight-tapered stems in cemented THA reduces subsidence but not cement damage. Biomaterials 1998;19:1773-9

32. Schmalzried TP, Jasty M, Harris WH. Periprosthetic bone loss in total hip arthroplasty: polyethylene wear debris and the concept of the effective joint space. J Bone Joint Surg [Am] 1992;74-A:849-63.

33. Anthony PP, Gie GA, Howie CR, Ling RS. Localised endosteal bone lysis in relation to the femoral components of cemented total hip arthroplasties. J Bone Joint Surg [Br] 1990;72-B:971-9

34. Breusch SJ, Schneider U, Kretzer J, Ewerbeck V, Lukoschek M. Effects of the cementing technique on cementing results concerning the coxal end of the femur. Orthopade 2000;29:260-70 (in German).

35. Noble PC, Box GG, Kamaric E, et al. The effects of aging on the shape of the proximal femur. Clin Orthop 1995;316:31-44.

36. Smith RW Jr, Walker RR. Femoral expansion in aging women: implications for osteoporosis and fractures. Science 1964;145:156-7. 